\title{
Article \\ DBU-Intercalated $\alpha$-Zirconium Phosphates as Latent Thermal Catalysts in the Reaction of Hexamethylene Diisocyanate and Phenol
}

\author{
Osamu Shimomura *(D), Hideki Kusu, Atsushi Ohtaka (D) and Ryôki Nomura \\ Department of Applied Chemistry, Osaka Institute of Technology, 5-16-1 Omiya, Ashahi-ku, \\ Osaka 535-8585, Japan; kusuhi-.chemical0108@hotmail.co.jp (H.K.); atsushi.otaka@oit.ac.jp (A.O.); \\ ryoki.nomura@oit.ac.jp (R.N.) \\ * Correspondence: osamu.shimomura@oit.ac.jp; Tel.: +81-6-6954-4269
}

check for updates

Citation: Shimomura, O.; Kusu, H.; Ohtaka, A.; Nomura, R. DBU-

Intercalated $\alpha$-Zirconium Phosphates as Latent Thermal Catalysts in the Reaction of Hexamethylene Diisocyanate and Phenol. Catalysts 2021, 11, 614. https://doi.org/ $10.3390 /$ catal11050614

Academic Editor: Manuel A. Fernandez-Rodriguez

Received: 14 April 2021

Accepted: 7 May 2021

Published: 11 May 2021

Publisher's Note: MDPI stays neutral with regard to jurisdictional claims in published maps and institutional affiliations.

Copyright: (c) 2021 by the authors. Licensee MDPI, Basel, Switzerland. This article is an open access article distributed under the terms and conditions of the Creative Commons Attribution (CC BY) license (https:/ / creativecommons.org/licenses/by/ $4.0 /)$.

\begin{abstract}
The catalytic activity of 1,8-diazabicyclo [5,4,0]undec-7-ene-intercalated $\alpha$-zirconium phosphates $(\alpha-\mathrm{ZrP} \cdot \mathrm{DBU})$ as thermal latent catalysts in the reaction of hexamethylene diisocyanate (HDI) and phenol was investigated. $\alpha-\mathrm{ZrP}$ intercalation compounds with varying amounts of DBU $(\alpha-$ $\mathrm{ZrP} \cdot \mathrm{xDBU}$, where $\mathrm{x}=0.58,0.44,0.22$, and 0.10 ) were prepared. The reaction of HDI and phenol with $\alpha$-ZrP.DBU was carried out at varying temperatures for 30 min periods. The $\alpha$-ZrP.DBU showed high catalytic activity in the reaction of HDI-phenol under heating conditions. The $\alpha$-ZrP.DBU extended the pot lifetimes at $25^{\circ} \mathrm{C}$.
\end{abstract}

Keywords: $\alpha$-zirconium phosphate; intercalation; latent thermal catalyst; urethane; pot life

\section{Introduction}

DBU (1,8-diazabicyclo [5,4,0]undec-7-ene) has been widely used as a catalyst for preparation of polyurethanes $[1,2]$. Generally, multifunctional alcohols and isocyanates are used to synthesize polyurethanes. In the preparation of polyurethane using DBU, an organic strong base catalyst, it is difficult to control the molding time due to the rapid reaction. Thus, it is very important to perform uniform mixing and molding of polyurethane to extend the pot lifetime. To resolve this problem, blocked isocyanates have been used to avoid unexpected reactions [3-6]. However, when using blocked reagents, low molecular weight deblocked compounds remain, which might affect the mechanical and thermal properties of the resulting polyurethane. Using castor oil as an alcohol component and toluene diisocyanate (TDI) as an isocyanate component, DBU-acetylacetone was added as a catalyst [7]. By adjusting the mixing ratio of DBU-acetylacetone for the suppression of DBU activity, the pot lifetime was extended and the components reacted at low temperature. However, the pot lifetime was $6 \mathrm{~min}$ without the addition of acetylacetone and 9-12 min with the addition of acetylacetone, which are too short for their use as latent thermosetting catalysts. Zivic et al. reported DBU derivatives of thioxanthone as photobase catalysts to promote the preparation of polyurethane [8]. Alsarraf reported that cyclic guanidine compounds reacted with two equivalents of isocyanates as latent catalysts [9]. In the preparation of polyurethane with these guanidine-isocyanate derivatives, the guanidine-isocyanate derivatives were first dissolved in THF. We hoped to avoid using organic solvents in the polymerization reaction. Recently, we reported that DBU-intercalated $\alpha$-zirconium phosphate $(\alpha-Z r P \cdot D B U)$ served as a latent thermal catalyst in the reaction of epoxy resins. The $\alpha$-ZrP.DBU catalyst can be obtained simply by mixing DBU and $\alpha-\mathrm{ZrP}$ in methanol at ambient temperature [10]. The intercalated compound of $\alpha-\mathrm{ZrP}$.DBU is expected to possess different reactivity with organic compounds and organic salts. We examined herein the catalytic activity of $\alpha$-ZrP.DBU in the reaction of hexamethylene diisocyanate (HDI) and phenol as a model reaction in polyurethane synthesis. 


\section{Results and Discussion}

In the preparation of polyurethane using a base catalyst, the reaction is very rapid and it is difficult to maintain the pot life to obtain uniform resins. Hence, we studied how to extend the time for uniform mixing and molding by using DBU-intercalated $\alpha$ zirconium phosphate as a thermal latent catalyst for polyurethane synthesis. We previously reported that DBU-intercalated $\alpha-\mathrm{ZrP}\left(\alpha-\mathrm{ZrP}\right.$-DBU) showed high stability at $40{ }^{\circ} \mathrm{C}$ and high reactivity at $120^{\circ} \mathrm{C}$ in the reaction of glycidyl phenyl ether (GPE) and hexahydro4 -methylphthalic anhydride (MHHPA) [11]. To prepare $\alpha$-ZrP intercalation compounds with various DBU contents, $\mathrm{DBU}$ and $\alpha-\mathrm{ZrP}$ were simply mixed in methanol. The compositions were estimated by elemental analyses as shown in Table 1 . The charge molar ratio of $\alpha-\mathrm{ZrP}$ to $\mathrm{DBU}(\mathrm{DBU} / \mathrm{ZrP}$ ) was $1.0,0.5,0.25$, or 0.10 . The DBU content of the intercalation compounds was determined by elemental analyses and were found to be $\mathrm{Zr}\left(\mathrm{HPO}_{4}\right) \cdot 0.58 \mathrm{DBU} \cdot 2.2 \mathrm{H}_{2} \mathrm{O}, \mathrm{Zr}\left(\mathrm{HPO}_{4}\right) \cdot 0.44 \mathrm{DBU} \cdot 1.7 \mathrm{H}_{2} \mathrm{O}, \mathrm{Zr}\left(\mathrm{HPO}_{4}\right) \cdot 0.22 \mathrm{DBU} \cdot 1.8 \mathrm{H}_{2} \mathrm{O}$, and $\mathrm{Zr}\left(\mathrm{HPO}_{4}\right) \cdot 0.10 \mathrm{DBU} \cdot 1.6 \mathrm{H}_{2} \mathrm{O}$, respectively. These compounds are abbreviated as, e.g., $\alpha-$ $\mathrm{ZrP} \cdot 0.58 \mathrm{DBU}$. Basal distances of $14.0 \AA\left(2 \theta=6.3^{\circ}\right)$ for $\alpha$-ZrP·0.58DBU, $13.4 \AA\left(2 \theta=6.6^{\circ}\right)$ and $12.3 \AA\left(2 \theta=7.2^{\circ}\right)$ for $\alpha$-ZrP· $0.44 \mathrm{DBU}, 12.1 \AA\left(2 \theta=7.3^{\circ}\right)$ for $\alpha$-ZrP· $0.25 \mathrm{DBU}$, and $12.1 \AA$ $\left(2 \theta=7.3^{\circ}\right)$ for $\alpha$-ZrP.0.10DBU were estimated from XRD patterns as shown in Figure 1 . The basal distances for all intercalated $\alpha$-ZrP.DBU compounds were expanded from pristine $\alpha-\operatorname{ZrP}\left(7.6 \AA, 2 \theta=11.7^{\circ}\right)$.

Table 1. Composition determined by elemental analysis and basal distance

\begin{tabular}{cccccc}
\hline Catalyst & $\mathbf{C ~ ( \% )}$ & $\mathbf{H ~ ( \% )}$ & $\mathbf{N ~ ( \% )}$ & $\boldsymbol{d}(\mathbf{A})$ & Composition \\
\hline a-ZrP·0.58DBU & 14.99 & 3.84 & 3.96 & 14.0 & $\mathrm{Zr}(\mathrm{HPO})_{2} \cdot 0.58 \mathrm{DBU} \cdot 2.2 \mathrm{H}_{2} \mathrm{O}$ \\
\hline a-ZrP·0.44DBU & 11.78 & 3.30 & 3.24 & $13.4,12.3$ & $\mathrm{Zr}\left(\mathrm{HPO}_{4}\right)_{2} \cdot 0.44 \mathrm{DBU} \cdot 1.7 \mathrm{H}_{2} \mathrm{O}$ \\
\hline a-ZrP·0.22DBU & 6.38 & 2.63 & 1.75 & 12.1 & $\mathrm{Zr}\left(\mathrm{HPO}_{4}\right)_{2} \cdot 0.22 \mathrm{DBU} \cdot 1.8 \mathrm{H}_{2} \mathrm{O}$ \\
\hline a-ZrP·0.10DBU & 3.12 & 2.10 & 0.84 & 12.1 & $\mathrm{Zr}\left(\mathrm{HPO}_{4}\right)_{2} \cdot 0.10 \mathrm{DBU} \cdot 1.6 \mathrm{H}_{2} \mathrm{O}$ \\
\hline
\end{tabular}

The ${ }^{31} \mathrm{P}$ MAS NMR spectra of the $\alpha$-ZrP.DBU compounds are shown in Figure 2 . The ${ }^{31} \mathrm{P}$ MAS NMR spectra showed multiple peaks for $\alpha$-ZrP.0.58DBU $(-21.0,-23.0,-24.0)$, $\alpha$-ZrP·0.44DBU (-19.0, -22.4), $\alpha$-ZrP·0.22DBU $(-15.4,-16.8,-17.5,-22.0,-23.9)$, and $\alpha-$ $\mathrm{ZrP} \cdot 0.10 \mathrm{DBU}(-21.9,-23.2)$. A single peak for pristine $\alpha-\mathrm{ZrP}$ was observed at $\delta-20.1$ [12]. The multiple peaks for the $\alpha$-ZrP.DBU compounds due to the interactions of the different positions of DBU and $\mathrm{H}_{2} \mathrm{O}$ into the layers of $\alpha-\mathrm{ZrP}$.

To determine the activity of the $\alpha$-ZrP.DBU compounds, the reaction of HDI-phenol with $\alpha$-ZrP.DBU compounds was evaluated as shown in Scheme 1. The conversion of phenols with $\alpha$-ZrP.DBU as a function of temperature was estimated by ${ }^{1} \mathrm{H}-\mathrm{NMR}$ analyses as shown in Supplementary Materials. A signal due to protons at the $o$-position of the starting phenol was observed at $\delta 6.83$. In the reaction product of urethane, a signal due to protons at the $m$-position was observed at $\delta$ 7.35. The conversions were determined by the ratio of these two peak areas.

For the reaction of HDI-phenol with $\alpha$-ZrP.DBU compounds, Figure 3 shows the conversion of phenols after $30 \mathrm{~min}$ as a function of temperature during the reaction with SA$102(\square), \alpha-Z r P \cdot 0.58 D B U(\square), \alpha-Z r P \cdot 0.44 \mathrm{DBU}(\diamond), \alpha-\mathrm{ZrP} \cdot 0.22 \mathrm{DBU}(\triangle)$, and $\alpha-\mathrm{ZrP} \cdot 0.10 \mathrm{DBU}$ (○). For U-cat SA-102 (DBU salt of 2-ethylhexanoate abbreviated as SA-102), a commercial DBU salt catalyst, the conversion was $98 \%$ at $25{ }^{\circ} \mathrm{C}$ for $30 \mathrm{~min}$. The conversion with $\alpha$-ZrP.0.58DBU was $86 \%$ at $25{ }^{\circ} \mathrm{C}$ for $30 \mathrm{~min}$. For $\alpha$-ZrP.0.44DBU, $\alpha-\mathrm{ZrP} \cdot 0.22 \mathrm{DBU}$, and $\alpha$-ZrP.0.10DBU catalysts, the conversions were all lower at ca. $10 \%$ at $25^{\circ} \mathrm{C}$ for $30 \mathrm{~min}$. However, the conversions with $\alpha-\mathrm{ZrP} \cdot 0.44 \mathrm{DBU}, \alpha-\mathrm{ZrP} \cdot 0.22 \mathrm{DBU}$, and $\alpha-\mathrm{ZrP} \cdot 0.10 \mathrm{DBU}$ were about $90 \%$ at $60{ }^{\circ} \mathrm{C}$ for $30 \mathrm{~min}$. Thus, these $\alpha$-ZrP.0.44DBU, $\alpha-Z r P \cdot 0.22 \mathrm{DBU}$, and $\alpha-$ $\mathrm{ZrP} \cdot 0.10 \mathrm{DBU}$ catalysts showed very low conversions of the reaction of phenols at $25^{\circ} \mathrm{C}$ but the reaction proceeded smoothly at $60^{\circ} \mathrm{C}$. 
(a)

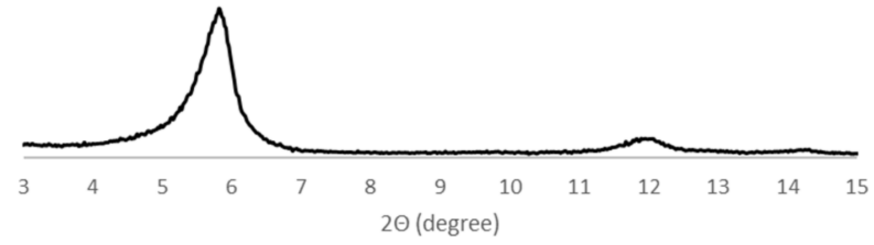

(b)

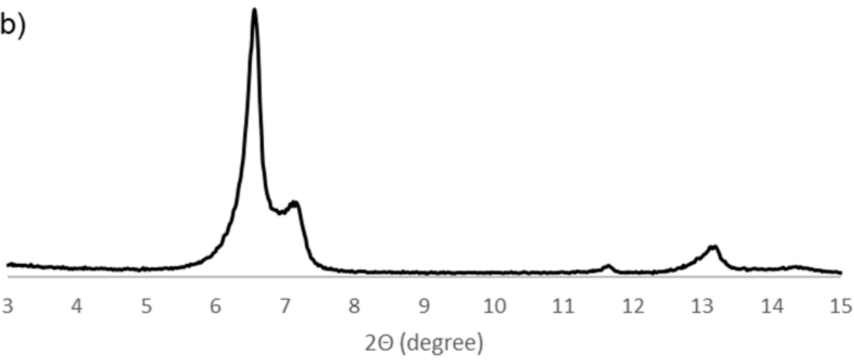

(c)

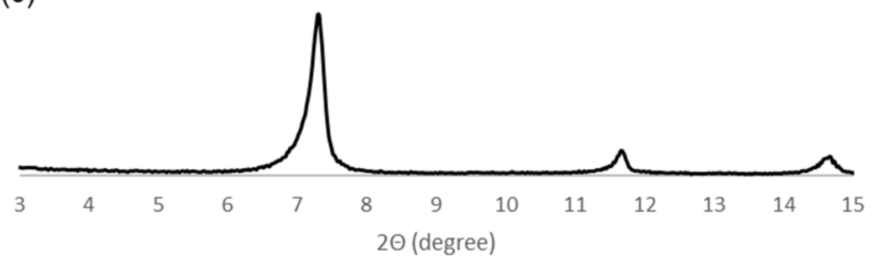

(d)

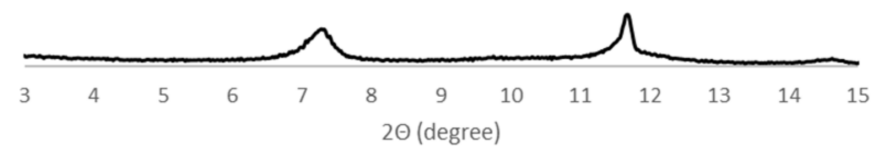

(e)

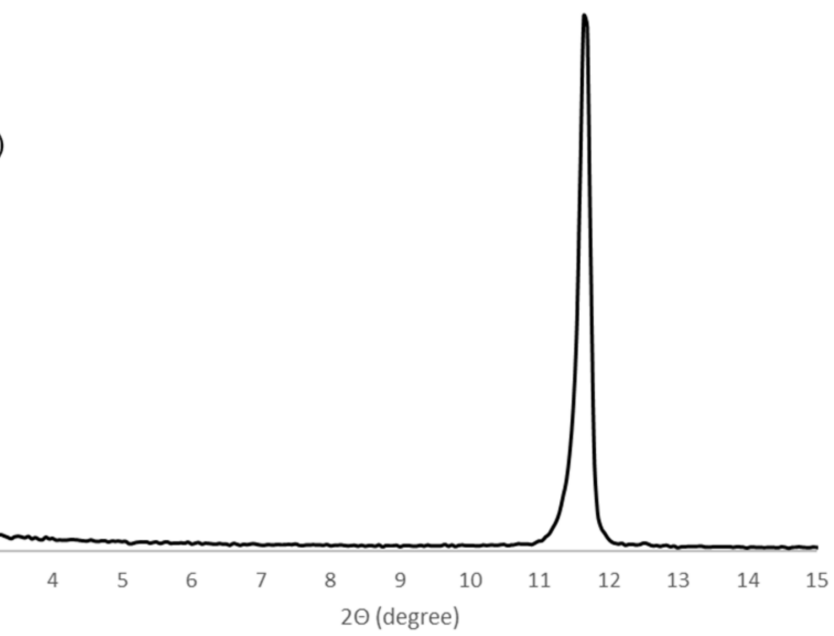

Figure 1. XRD patterns for (a) $\alpha$-ZrP·0.58DBU, (b) $\alpha$-ZrP·0.44DBU, (c) $\alpha-Z r P \cdot 0.22 D B U$, (d) $\alpha$ $\mathrm{ZrP} \cdot 0.10 \mathrm{DBU}$, and (e) pristine $\alpha-\mathrm{ZrP}$. 
(a)

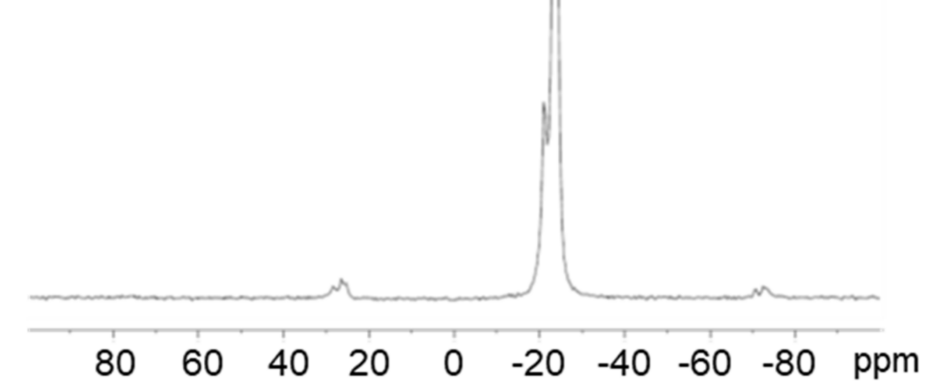

(b)

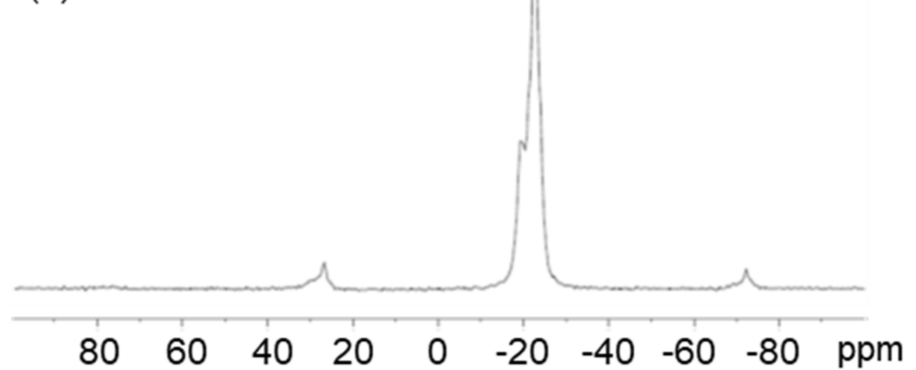

(c)

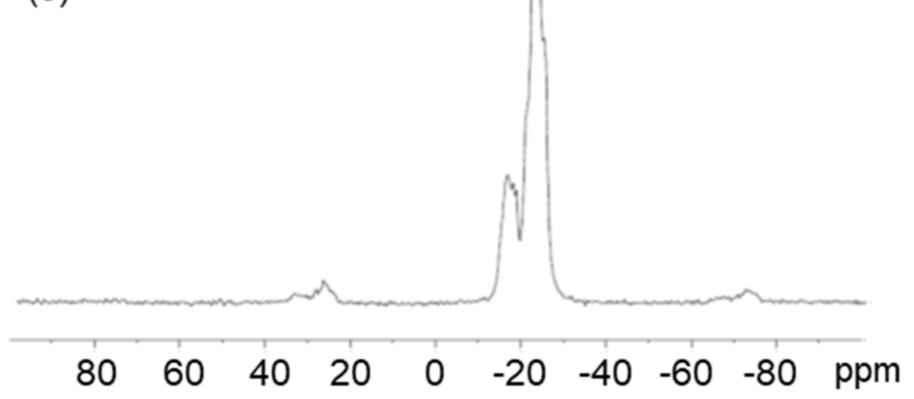

(d)

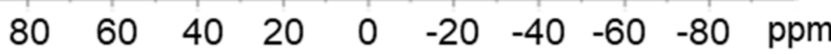

Figure 2. ${ }^{31} \mathrm{P}$ NMR spectra of (a) $\alpha-\mathrm{ZrP} \cdot 0.58 \mathrm{DBU}$, (b) $\alpha-\mathrm{ZrP} \cdot 0.44 \mathrm{DBU}$, (c) $\alpha-\mathrm{ZrP} \cdot 0.22 \mathrm{DBU}$, and (d) $\alpha-\mathrm{ZrP} \cdot 0.10 \mathrm{DBU}$. 


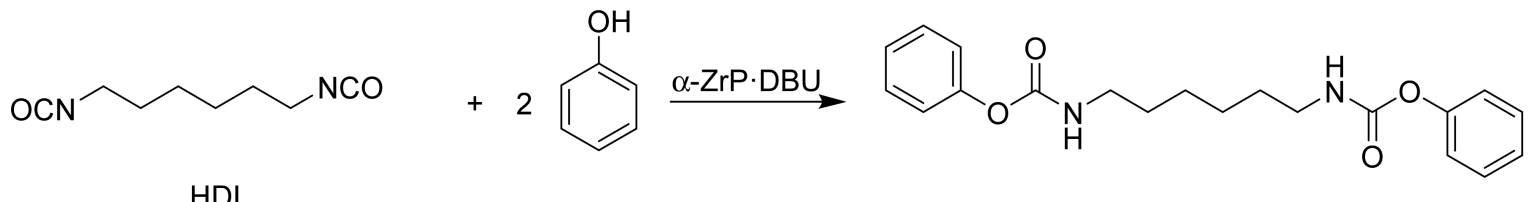

HDI

Scheme 1. Reaction of HDI and phenol with $\alpha$-ZrP DBUs.

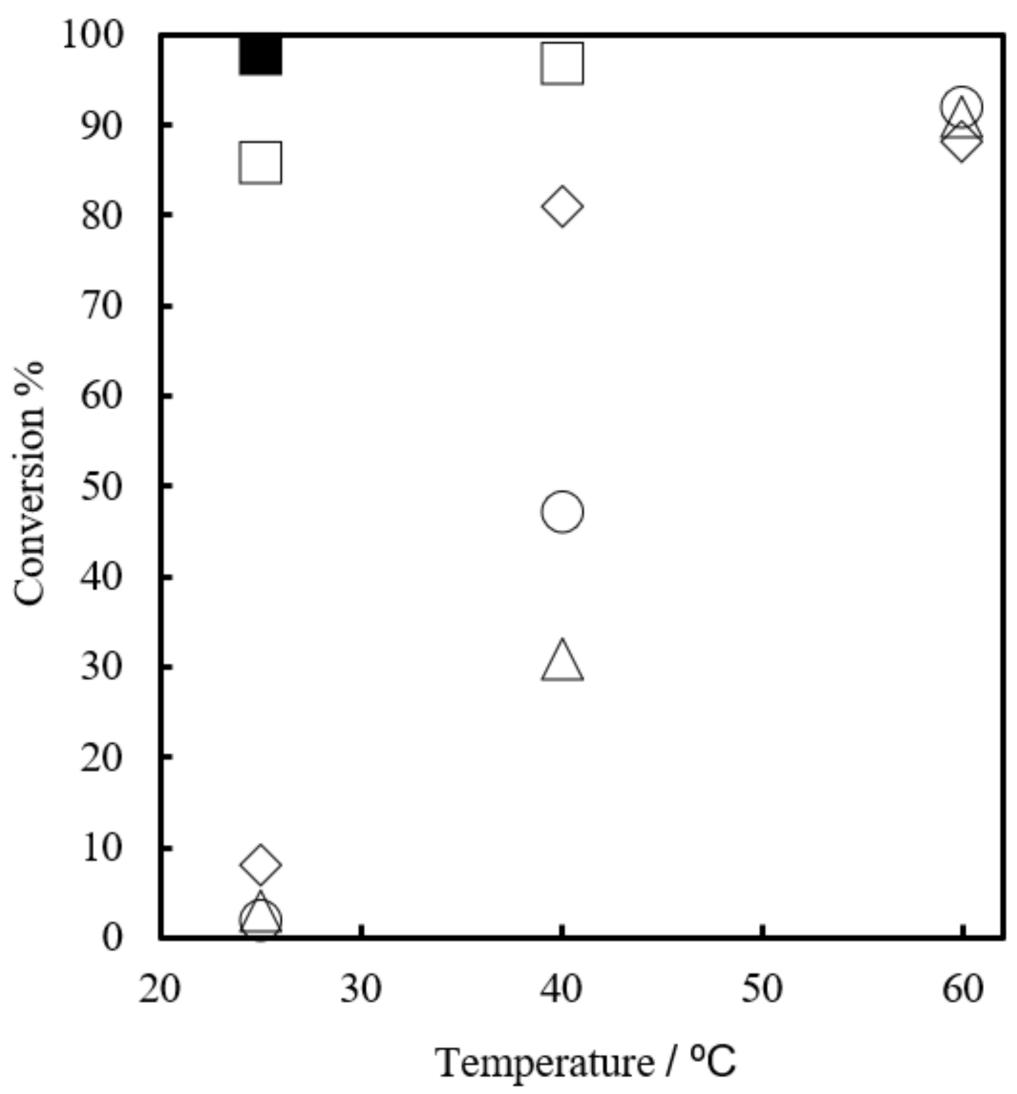

Figure 3. The conversion of phenol after $30 \mathrm{~min}$ as a function of temperature during reaction with SA-102 (ם), $\alpha$-ZrP·0.58DBU $(\square), \alpha-Z r P \cdot 0.44 \mathrm{DBU}(\diamond), \alpha-\mathrm{ZrP} \cdot 0.22 \mathrm{DBU}(\triangle)$, and $\alpha-\mathrm{ZrP} \cdot 0.10 \mathrm{DBU}(\bigcirc)$.

The pot lifetimes for the $\alpha$-ZrP.DBU compounds were evaluated at $25{ }^{\circ} \mathrm{C}$ as shown in Figure 4. The pot lifetimes at $25{ }^{\circ} \mathrm{C}$ for the SA-102 and $\alpha-\mathrm{ZrP} \cdot 0.58 \mathrm{DBU}$ catalysts were not determined. The conversion was $24 \%$ with $\alpha-\mathrm{ZrP} \cdot 0.44 \mathrm{DBU}$ at $25^{\circ} \mathrm{C}$ for $1 \mathrm{~h}$. The conversions with $\alpha$-ZrP·0.22DBU and $\alpha-\mathrm{ZrP} \cdot 0.10 \mathrm{DBU}$ were $22 \%$ and $18 \%$ at $25^{\circ} \mathrm{C}$ for $2 \mathrm{~h}$. These catalysts could extend the pot lifetime at $25^{\circ} \mathrm{C}$. The conversion with $\alpha-\mathrm{ZrP} \cdot 0.44 \mathrm{DBU}$ for $1.5 \mathrm{~h}$ was $36 \%$ and with $\alpha-\mathrm{ZrP} \cdot 0.22 \mathrm{DBU}$ and $\alpha-\mathrm{ZrP} \cdot 0.10 \mathrm{DBU}$ were $55 \%$ and $35 \%$ for $4 \mathrm{~h}$. The pot life for $30 \%$ conversion was over $1.5 \mathrm{~h}$ for $\alpha$-ZrP.0.44DBU and $4 \mathrm{~h}$ for $\alpha$-ZrP.0.22DBU and $\alpha$-ZrP.0.10DBU. The correlations of time-conversion with $\alpha-\mathrm{ZrP} \cdot 0.22 \mathrm{DBU}$ and $\alpha$ $\mathrm{ZrP} \cdot 0.10 \mathrm{DBU}$ showed good liner approximation, and the formulas were $\mathrm{C}(\%)=12.8 \mathrm{~T}(\mathrm{~h})$ and $\mathrm{C}(\%)=8.5 \mathrm{~T}(\mathrm{~h})(\%$ Conversion $=$ coefficient $\times$ hour time $)$ for $\alpha-\mathrm{ZrP} \cdot 0.22 \mathrm{DBU}$ and $\alpha-\mathrm{ZrP} \cdot 0.10 \mathrm{DBU}$ respectively.

The reaction behavior suggested that the salt type catalyst SA-102 was rapidly dissociated and reacted to produce urethane in high conversion at $25^{\circ} \mathrm{C}$. The pot lifetime for the $\alpha-\mathrm{ZrP}$.DBU catalysts depended on the DBU content in $\alpha-\mathrm{ZrP}$ and the catalysts showed high activity at $60{ }^{\circ} \mathrm{C}$. The difference in the activities of SA-102 and $\alpha-\mathrm{ZrP}$.DBU compounds might be caused by the protection of DBU in the interlayer of $\alpha-\mathrm{ZrP}$. 


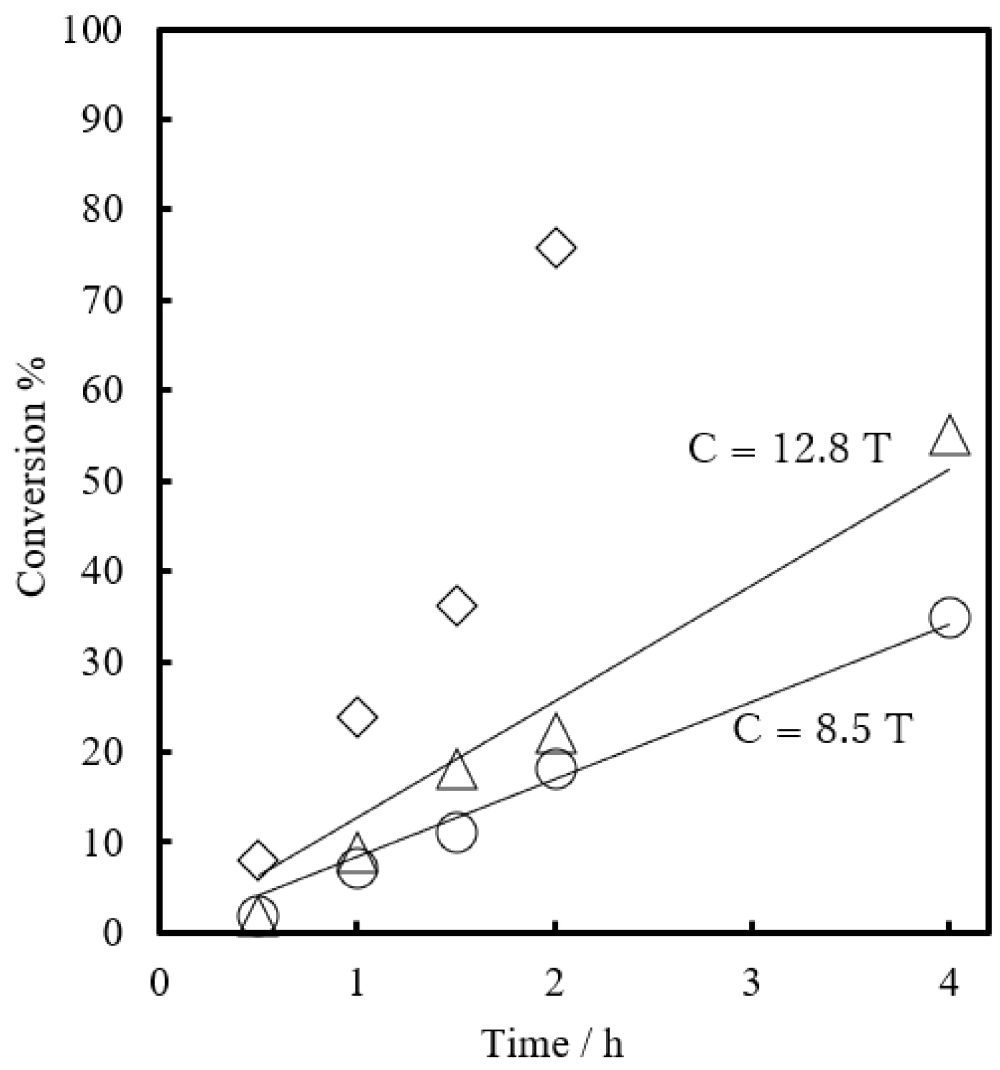

Figure 4. Conversion of phenol as a function of time during reaction with $\alpha-\mathrm{ZrP} \cdot 0.44 \mathrm{DBU}(\diamond)$, $\alpha-\mathrm{ZrP} \cdot 0.22 \mathrm{DBU}(\triangle)$, and $\alpha-\mathrm{ZrP} \cdot 0.10 \mathrm{DBU}(\bigcirc)$ at $25^{\circ} \mathrm{C}$.

\section{Experimental Section}

\subsection{Materials}

$\mathrm{Zr}\left(\mathrm{HPO}_{4}\right)_{2} \cdot \mathrm{H}_{2} \mathrm{O}(\mathrm{CZP}-100)$ was purchased from Daiichi Kigenso Kagaku Kogyo Co., Ltd. Hexamethylene diisocyanate (HDI), and 1,8-diazabicyclo[5.4.0]-7-undecene (DBU) were purchased from Tokyo Chemical Industry Co., Ltd. (Tokyo, Japan). Phenol was purchased from Kanto Chemical Co., Inc. (Tokyo, Japan). Solvents were used as received without further purification. U-CAT SA102 was purchased from San-Apro, Ltd., (Kyoto, Japan).

\subsection{Measurements}

X-ray diffraction (XRD) patterns were obtained using a RIGAKU RINT2200 with $\mathrm{CuK} \alpha$ radiation over a scan range of $3-15^{\circ}$ at a rate of $2^{\circ} \mathrm{min}^{-1}$. NMR spectra in solution were recorded on a Varian Unity-300 (300 MHz) spectrometer (Palo Alto, CA, USA) and a JEOL JNM-ECZS (400 MHz) spectrometer (Tokyo, Japan) using tetramethylsilane (TMS) as an internal standard. The contents of alkylamine and water in the intercalation compounds of $\alpha$-ZrP were measured using a Perkin Elmer CHN microanalyzer. ${ }^{31} \mathrm{P}$ MAS NMR spectra were recorded on a BRUKER AVANCEIII600WB NMR spectrometer equipped with $4.0 \mathrm{~mm}$ MAS probe head.

\subsection{Preparation of $D B U$-Intercalated $\alpha-\operatorname{ZrP}(\alpha-\mathrm{ZrP} \cdot 0.10 \mathrm{DBU})$}

The intercalation of DBU into the layers of $\alpha-\mathrm{Zr}\left(\mathrm{HPO}_{4}\right)_{2} \cdot \mathrm{H}_{2} \mathrm{O}(\alpha-\mathrm{ZrP})$ was carried out by slightly modifying a previously reported method [10]. Approximately $5.0 \mathrm{~g}$ of $\alpha-\mathrm{ZrP}$ was added to $33 \mathrm{~mL}$ of a DBU $0.256 \mathrm{~g}(1.68 \mathrm{mmol})$ methanol solution. The reaction mixture was then allowed to stand at ambient temperature for $24 \mathrm{~h}$, following which the product was collected by centrifugation at $5000 \mathrm{rpm}$ for $15 \mathrm{~min}$ and washed with methanol five times. The resulting residue was dried under vacuum. The preparation of $\alpha-\mathrm{ZrP} \cdot 0.58 \mathrm{DBU}$, 
$\alpha-\mathrm{ZrP} \cdot 0.44 \mathrm{DBU}$, and $\alpha-\mathrm{ZrP} \cdot 0.22 \mathrm{DBU}$ was carried out by varying the molar ratio of $\mathrm{DBU} / \mathrm{Zr}$ to $1,0.5$, and 0.25 , respectively.

\subsection{Typical Model Reaction Procedure of HDI and Phenol}

A mixture of phenol (944 mg, $10.0 \mathrm{mmol}$ ) and $\alpha$-ZrP·0.44DBU $(4.2 \mathrm{mg}$, DBU content: $4.9 \mu \mathrm{mol}, 0.1 \mathrm{~mol} \%$ for HDI) was stirred. After $5 \mathrm{~min}$, HDI ( $862 \mathrm{mg}, 5.1 \mathrm{mmol})$ was added to the mixture, which was then heated at $40{ }^{\circ} \mathrm{C}$. After $30 \mathrm{~min}$, a small aliquot of the reaction mixture was dissolved in $\mathrm{CDCl}_{3}$ and its ${ }^{1} \mathrm{H}$-NMR spectrum was acquired to determine the extent of conversion. For the reactions of HDI and phenol with the $\alpha-\mathrm{ZrP} \cdot 0.58 \mathrm{DBU}, \alpha-$ $\mathrm{ZrP} \cdot 0.22 \mathrm{DBU}$, and $\alpha-\mathrm{ZrP} \cdot 0.10 \mathrm{DBU}$ catalysts, the DBU equivalents were unified to $0.1 \mathrm{~mol} \%$ for HDI.

\section{Conclusions}

We prepared various DBU-intercalated compounds of $\alpha-\mathrm{ZrP}$ with DBU/Zr molar ratios of $0.58,0.44,0.22$, and 0.10 . The catalytic activity of $\alpha$-ZrP.DBU compounds in the reaction of HDI and phenol was investigated. The $\alpha$-ZrP $\cdot 0.58 \mathrm{DBU}$ catalyst did not have an appreciable pot lifetime at $25^{\circ} \mathrm{C}$ for $30 \mathrm{~min}$. The $\alpha$-ZrP-0.44DBU catalyst showed a $24 \%$ pot lifetime in the conversion at $25^{\circ} \mathrm{C}$ for $1 \mathrm{~h}$. The $\alpha$-ZrP·0.22DBU and $\alpha-\mathrm{ZrP} \cdot 0.20 \mathrm{DBU}$ had $22 \%$ and $18 \%$ pot lifetimes at $25^{\circ} \mathrm{C}$ for $2 \mathrm{~h}$. These catalysts showed high reactivity at $60{ }^{\circ} \mathrm{C}$ for $30 \mathrm{~min}$. These catalysts can be applied for the syntheses of polyurethanes. The polymerization of diols and diisocyanates with $\alpha$-ZrP.DBU would be studied further.

Supplementary Materials: The following are available online at https://www.mdpi.com/article/10 $.3390 /$ catal11050614/s1, Figure S1: The ${ }^{1} \mathrm{H}-\mathrm{NMR}$ spectra after the reaction of HDI and phenol with a) $\alpha$-ZrP·0.10DBU at $25^{\circ} \mathrm{C}$ and b) $\alpha$-ZrP·0.58DBU at $40{ }^{\circ} \mathrm{C}$ for $30 \mathrm{~min}$.

Author Contributions: O.S. conceived, designed and wrote the article; H.K. performed the experiments; A.O. and R.N. contributed to a helpful discussion. All authors have read and agreed to the published version of the manuscript.

Funding: This research received no external funding.

Data Availability Statement: Data is contained within the article.

Conflicts of Interest: The authors declare no conflict of interest.

\section{Abbreviations}

$\begin{array}{ll}\text { Abbreviation } & \text { Compound Name } \\ \alpha \text {-ZrP } & \alpha \text {-zirconium phosphate } \\ \text { DBU } & \text { 1,8-diazabicyclo[5,4,0]undec-7-ene } \\ \text { HDI } & \text { hexamethylene diisocyanate } \\ \text { SA-102 } & \text { DBU salt of 2-ethylhexanoate }\end{array}$

\section{References}

1. Alsarraf, J.; Ammar, Y.A.; Robert, F.; Cloutet, E.; Cramail, H.; Landais, Y. Cyclic guanidines as efficient organocatalysts for the synthesis of polyurethanes. Macromolecules 2012, 45, 2249-2256. [CrossRef]

2. Sardon, H.; Pascual, A.; Mecerreyes, D.; Taton, D.; Cramail, H.; Hedrick, J.L. Synthesis of polyurethanes using organocatalysis: A perspective. Macromolecules 2015, 48, 3153-3165. [CrossRef]

3. Delebecq, E.; Pascault, J.P.; Boutevin, B.; Ganachaud, F. On the versatility of urethane/urea bonds: Reversibility, blocked isocyanate, and non-isocyanate polyurethane. Chem. Rev. 2013, 113, 80-118. [CrossRef] [PubMed]

4. Kalaimani, S.; Nasar, A.S. Catalysis of deblocking and cure reactions of easily cleavable phenol blocked polyisocyanates with poly(polytetrahydrofuran carbonate) diol. Eur. Polym. J. 2017, 91, 221-231. [CrossRef]

5. Fedoseev, M.S.; Noskova, O.A.; Derzhavinskaya, L.F. Synthesis and properties of blocked Di- and polyisocyanates. Polym. Sci. Ser. D 2016, 9, 199-204. [CrossRef]

6. Nasar, A.S.; Kalaimani, S. Synthesis and studies on forward and reverse reactions of phenol-blocked polyisocyanates: An insight into blocked isocyanates. RSC Adv. 2016, 6, 76802-76812. [CrossRef] 
7. Nakagawa, K.; Nishimura, M. Latent Crosslinking Catalysts, Their Polyurethane Compositions, and Their Two-Component, Fast-Curing, and Heat-Curable Adhesives with Long Pot Life. 2004-222703, 2006037028, 20040730. 2006. Available online: https://www.j-platpat.inpit.go.jp/p0200 (accessed on 10 May 2021).

8. Zivic, N.; Sadaba, N.; Almandoz, N.; Ruipérez, F.; Mecerreyes, D.; Sardon, H. Thioxanthone-Based photobase generators for the synthesis of polyurethanes via the photopolymerization of polyols and polyisocyanates. Macromolecules 2020, 53, 2069-2076. [CrossRef]

9. Alsarraf, J.; Robert, F.; Cramail, H.; Landais, Y. Latent catalysts based on guanidine templates for polyurethane synthesis. Polym. Chem. 2013, 4, 904-907. [CrossRef]

10. Shimomura, O.; Sueto, R.; Kusu, H.; Ueoka, H.; Ohtaka, A.; Nomura, R. Effect of particle size of DABCO- and DBU-intercalated $\alpha$-zirconium phosphate as latent thermal catalysts in the reaction of glycidyl phenyl ether (GPE) and hexahydro-4-methylphthalic anhydride (MHHPA). J. Adhes. Soc. Jpn. 2018, 54, 258-263. [CrossRef]

11. Shimomura, O.; Nishisako, T.; Yamaguchi, S.; Ichihara, J.; Kirino, M.; Ohtaka, A.; Nomura, R. DABCO- and DBU-intercalated $\alpha$-zirconium phosphate as latent thermal catalysts in the copolymerization of glycidyl phenyl ether (GPE) and hexahydro-4methylphthalic anhydride (MHHPA). J. Mol. Catal. A Chem. 2016, 411, 230-238. [CrossRef]

12. Shimomura, O.; Maeno, K.; Ohtaka, A.; Yamaguchi, S.; Ichihara, J.; Sakamoto, K.; Nomura, R. Alkylamines-intercalated $\alpha$-zirconium phosphate as latent thermal anionic initiators. J. Polym. Sci. Part A Polym. Chem. 2014, 52, 1854-1861. [CrossRef] 